\title{
Identifying the success factors of knowledge management tools in research projects (Case study: A corporate university)
}

\section{Hamidreza Ghomi ${ }^{\mathrm{a}}$ and Farnaz Barzinpour ${ }^{\mathrm{b}^{*}}$}

${ }^{a}$ School of Progress Engineering, Iran University of Science \& Technology, Iran

${ }^{b}$ School of Industrial Engineering, Iran University of Science \& Technology, Iran

\section{H R O N I C L E}

Article history:

Received: March 23, 2018

Received in revised format: June

1,2018

Accepted: June 18, 2018

Available online:

June 18, 2018

Keywords:

Critical success factor

CSF

University

\section{Introduction}

Knowledge as a strategic asset must be managed so that organization can maintain its competitive operation (Bolisani \& Bratianu, 2017) and it plays a significant role in the growth, survival and performance of a knowledge-based economy (Huang \& Wu, 2010). Knowledge management emphasizes the creation of value, which means managing existing knowledge and turning it into useful knowledge in the organization. Impact of Knowledge Management (KM) on the organization's overall success has been widely acknowledged (Terzieva, 2014; Frey et al., 2009; Alekseev, 2010). However, what factors and how to cause its success, are key questions, which require extensive study. Corporate Universities, in addition to being a specific educational organization, also play a facilitating role in the organization's knowledge management. For this reason, some researchers consider them to be a part of the organization's knowledge management process (Crocetti, 2001; Rademakers, 2005; Wiig, 1997). The corporate university studied in this study, as a scientific research center, is no exception and needs to capture, manage

* Corresponding author

E-mail address: barzinpour@iust.ac.ir (F. Barzinpour)

C 2018 by the authors; licensee Growing Science, Canada doi: $10.5267 /$ j.msl.2018.6.006 
and take advantage of knowledge and information in order to improve the efficiency of its field of application. As with other science centers, the university, by defining its research and implementation, seeks to analyze the progressive problems, to add to its organizational knowledge, and to apply its findings in order to solve its scientific and organizational problems, or other scientific centers, through sharing and extracting the findings. Knowledge management tools, which are techniques and methods for the operating of knowledge management (Young, 2010), are important in this regard, and examining the factors influencing their success can contribute to the success of their use. In this regard, the questions are: What are the factors affecting the success of KM tools in the research projects of the corporate university?, What is the current status of these factors?, What is the priority of these factors? By answering these questions, the present study investigates the factors affecting the success of KM tools in the research projects of a corporate university.

\section{Literature and subject background}

Since the beginning of 1990, all companies in the world have been talking about knowledge management. Recent planners and modernists in information technology played an important role in the sudden emergence of knowledge management. KM development provided new tools for better knowledge sharing (Civi, 2000). KM tools and techniques have been designed to support business processes and enterprise projects in a more excellent manner (Young, 2010). The list of tools and techniques that the world's most successful organizations have used in KM initiatives are summarized in Table 1. These tools and techniques are not listed in any order, such as importance or hierarchy, but are categorized and listed into three groups of individual, organizational and information technology-based.

\section{Table 1}

KM tools and techniques (Ghomi, 2014)

\begin{tabular}{|c|c|c|}
\hline $\begin{array}{l}\text { Tools and techniques based on information } \\
\text { technology }\end{array}$ & $\begin{array}{l}\text { Tools and techniques based on organizational } \\
\text { approaches }\end{array}$ & $\begin{array}{l}\text { Tools and techniques based on individual ap- } \\
\text { proaches }\end{array}$ \\
\hline Social network analysis & Leader or senior management support & Direct concurrence \\
\hline Document libraries & Culture & Assistance to coworker \\
\hline Knowledge bases & Knowledge center & Reviews of learning \\
\hline Data bases & Identifying and sharing the best activities & Reviews after measurement \\
\hline Social networking services & Creating a knowledge strategy & Innovation \\
\hline Internet audiovisual protocol & Knowledge Audit & Knowledge house \\
\hline Advanced searching tools & Sustainable competitive advantage & Work communities \\
\hline Creating knowledge branches & Exit interview & Classification (science classification program) \\
\hline Identifying specialist & $\begin{array}{l}\text { Changing organizational structure (horizontal } \\
\text { structure) }\end{array}$ & Teacher-student method \\
\hline Collaborative virtual workspaces & Knowledge exhibition & Small articles \\
\hline Databases & Motivational Activities & Writings \\
\hline Learning in virtual spaces & Harvesting knowledge & Telling story \\
\hline Websites & Reworking & Apprenticeship \\
\hline Networks & Structured interview with experts & Dialogue \\
\hline Groupware & Contribute qualified staff in education & Work groups \\
\hline Knowledge sharing networks & Talking places and chat rooms & Apprenticeship \\
\hline Expert system & After-project evaluation method & Trust \\
\hline Recording learning and thoughts & Knowledge Map & Special session of leaned lesson \\
\hline Blank pages & Collaborative physical work space & - \\
\hline 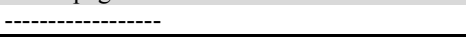 & workflow &  \\
\hline
\end{tabular}

To be able to use any KM tool, we need to know the success factors in implementing knowledge management in the organization and, with these factors, we may use the right tool. The success factors can be defined as "critical areas of planning and managerial measurement that must be provided to achieve effectiveness" (Saraph et al., 1989). In the language of knowledge management, the success factors are the activities and actions necessary to implement knowledge management. These factors must be created to provide its absence in the organization and, if any, be raised and developed. External factors such as environmental impacts are not taken into account because organizations do not control them in the implementation of knowledge management. Davenport et al. (1998), made an exploratory study of 31 projects in 24 companies. One of the objectives of this study was to determine the factors influencing the effectiveness of the plans. To this end, the performance of the plans was evaluated by using indicators similar to the evaluation indicators of other organizational change plans. According to studies, 18 projects 
succeeded, and five projects failed. In eight companies, judgment about the success or failure of the plans was early. Eight common success factors were identified as follows: 1. Top management support 2. Clear expression and promotion of knowledge management objectives 3. Connecting the knowledge management plan to unit economic performance 4. Multiple channels for knowledge transfer 5. Motivational rewards for users of knowledge management 6 . Standard and flexible knowledge structure 7. Strong technical and organizational infrastructure 8. Strong technical and organizational infrastructure 9. Knowledge-friendly culture. Sohrabi et al. (2009), in a research on the readiness for knowledge management, identified supporting change, change perspective, knowledge culture, structure and infrastructure as critical success factors for knowledge management. Supporting change includes education, management support, participation and incentive system; change perspective including benefits and advantages; harmony of change goals; need sense; knowledge culture including collaborative culture; open leadership environment; learning from mistakes and trust; structure including decentralization, formalization and group work; and infrastructure including information quality, access to infrastructure of information systems, verbal skills. According to Mathi (2004), leadership, training, patterning, performance evaluation, organizational policies, knowledge sharing and the structure of information systems are considered as the success factors for implementing knowledge management activities. Dixon (2000) identified two factors for the success of KM projects: 1. the alignment of knowledge management with organizational goals. 2. Identifying specific groups requires specific knowledge. Forcadell and Guadamillas (2002) showed the success of KM implementation in the form of seven factors focusing on organizational culture as shown in Fig. 1:

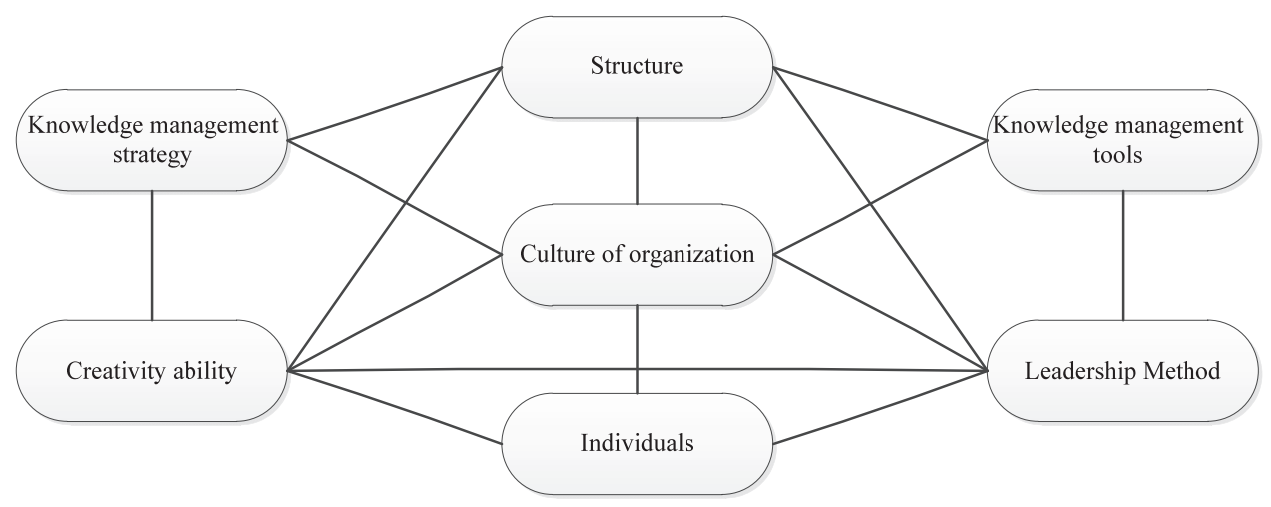

Fig. 1. Success Factors for Knowledge Management (Forcadell \& Guadamillas, 2002)

According to Demarest (1997), for successful knowledge management, where the knowledge process takes place, we must focus on three infrastructures: 1. Cultural Infrastructure 2. Organizational Infrastructure 3. Technical Infrastructure (Soliman \& Spooner, 2000). The Gartner Institute identified the alignment of knowledge management with strategies, the existence of organizational culture and organizational discipline for knowledge sharing, attention to human processes, and the necessity of a technology-based basis as the factors influencing knowledge management (Snyman \& Krugere, 2004). Chait (2000) found that insight and alignment, the management of four areas of content, culture, process and infrastructure, and the creation of effective culture were the success factors for KM initiatives. Alavi and Liedner (2001) studied executive managers in a managerial development program in terms of the success of the KM system and found that organizational and cultural problems related to motivating users to share and use knowledge are the most important problems. They also found that measuring the benefits of the KM system and using an integrated technology architecture that supports databases, communications, and search and retrieval functions are important. Holsapple and Joshi (2000) conducted a broad study to examine the factors affecting the success of knowledge management in organizations. They first extracted the set of factors from different sources. Then, by using the Delphi method, with university professors and industry experts in the field of knowledge management, they evaluated the factors ob- 
tained from the previous step. Finally, they proposed three main categories of factors, including management, resources, and environment, which are categorized as follows:

- The effects of management, including four main groups of coordination, control, measurement and leadership

- The effects of resources, including knowledge, human, materials, and finances resources

- The effects of environment, including competition, markets, time pressure, economic situation, conditions of government, etc.

In this study, it was reported that some items, such as technology and culture, must be investigated as factors, not components of other factors. For example, culture was not stated explicitly, but as an element called the source of knowledge. Even though on the basis of knowledge management, culture is a very important issue and must be considered as a factor. There were also some factors that could have been mentioned, such as infrastructure, communication, education, organizational planning, strategy, and bonus issues. Based on these studies, leadership and senior management support were identified as factors. Resources such as suitable financial support, staff skill levels and identifying knowledge resources were mentioned significant. Koskinen et al. (2003) studied tacit knowledge as a driving force in technology companies by using ten small technology companies; the key to the success of the KM system was the ability to identify, acquire, and transfer the company's essential tacit knowledge. According to Cross and Baird (2000), knowledge management does not improve organizational performance by merely using technology in the acquisition and sharing of lessons learned from past experiences. However, for this purpose, knowledge management must increase organizational learning through the creation of organizational memory. In order to examine this view, 22 projects were studied. The result was that improving organizational learning increases the chances of success in knowledge management. Sage and Rouse (1999), by reviewing the history of innovation and technology, considered focusing on modeling processes in order to identify requirements and resources of knowledge, the existence of a knowledge management strategy for identifying the knowledge used and its users, rewarding and motivating for using the knowledge management system, the existence of attraction Infrastructure, searching, retrieving and displaying knowledge, creating a specific knowledge structure at the organization level, identifying clear goals for the KM system, and measuring and assessing the effectiveness of knowledge management as factors in managing knowledge. According to Kemp et al. (2001), explicit goals, strong financial support, true expectations, systemic approach, flexible framework, evolutionary process and technical maturity are the key success factors of knowledge management. Hung et al. (2005) emphasized the commitment and leadership of senior management, employee engagement, trusted teamwork, employee empowerment, information systems infrastructure and performance evaluation as success factors in implementing knowledge management in an organization. They also made a comprehensive classification of the success factors of knowledge management, which is presented in Table 2.

\section{Table 2}

Classification of Knowledge Management Success Factors (Hung et al., 2005)

\begin{tabular}{ll}
\hline Success factors dimensions & Relevant research \\
Honesty and open organizational culture & $\begin{array}{l}\text { (Davenport et al., 1998. Beckman, 1999. Gricault, 1999. Ryan and Prebotok, 2001. Wilde et al., 2002). } \\
\text { Moffat et al., 2003) }\end{array}$ \\
$\begin{array}{l}\text { Leadership and senior management com- } \\
\text { mitment }\end{array}$ & $\begin{array}{l}\text { (Davenport et al., 1998. Beckman, 1999. Grico, 1999. Ryan and Prebotok, 2001. Moffett et al., 2003; } \\
\text { Wanbran, 1999; Des and Piscons, 2000). }\end{array}$ \\
Employees participation & (Ryan and Prebotok, 2001. Mouft et al., 2003, B. Brin and Chez, 1995. Copper Kahn, 1999. Wilson and \\
Staff training & Ashey, 1999) \\
Group work & (Moffett et al., 2003, Greengard, 1998. Kuhn \& Baker, 1999) \\
Encouraging staff & (Girant, 1998. Grangeard, 1998. Ryan and Prebotok, 2001. Moffat et al., 2003) \\
Information systems infrastructure & (Entry, 1997. Martinez, 1998. Erich, 1998. Diwall, 1999. Vorspage, 1999. Moffett et al., 2003) \\
performance evaluation & (King, 1996. Davenport and colleagues, 1998. Grico, 1999. Bauderai and Coyleard, 1999. Sawari, 1999. \\
Patterning & (Martinez, 1998. Bassie and Wonbardin, 1999. Pearson, 1999. Barski, 2000. Moffat et al., 2003) \\
Knowledge structure & (Davis, 1996. Drew, 1997. Dai and Wendler, 1998. A. Del and Grains, 1998. Moffett et al., 2003) \\
\hline & (Davenport \& Claire, 1998. Beckman, 1999. Gricault, 1999. Hiskins, 1999. Tienan, 1999. Hassie et al., \\
\hline
\end{tabular}


The most important factors affecting the success of KM tools in research projects from the perspective of literature are as follows:

Culture: Organizational culture is an essential factor for the success of knowledge management (Davenport et al., 1998; Mårtensson, 2000). Culture determines fundamental ideas, social values and norms governing the behavior and function of individuals in the organization. In relation to organizational culture, trust, participation, encouragement and participatory leadership are development factors of organizational goals (Forcadell \& Guadamillas, 2002). In general, the culture supporting the management of knowledge considers a high value for knowledge and encourages the creation, sharing and its use. Based on studies, the culture is the biggest barrier for companies in building a knowledge-based organization (Chaudhry, 2005).

Information technology: knowledge management in practice requires information technology (Bharadwaj, 2000; Wade \& Hulland, 2004; Tanriverdi, 2005). Every step of the KM process, such as the pursuit of knowledge assets, can be enhanced by information technology (Tseng, 2008).

Strategy and goal: In order to achieve future goals, organizations must shift their knowledge management activities towards real efforts based on a strategy or a clear program. Therefore, one of the factors of success in KM is to have explicit strategy with proper implementation planning, form a formal knowledge management strategy throughout the organization and provide training programs and enhancing the capabilities of the new knowledge management (Leibowitz, 1999). The strategy is the basis for applying the organization's capabilities and resources to realize the goals of KM. Even though different strategies have been proposed for implementing knowledge management, the strategy must be chosen according to the context and situation of the organization concerned (Sunassee \& Sewry, 2003).

Organizational Infrastructure: The purpose of an organizational infrastructure is to create a set of roles and groups for carrying out the tasks related to knowledge (Davenport et al., 1998). Although some of the functions existing in the organization, such as human resource management and information technology deal with knowledge-related issues, the creation of a formal independent team with special responsibility of knowledge management is essential. The roles of this group can be assigned to the existing posts in the organization or created new posts for it.

Employee motivation: The success of KM requires encouraging employees to apply their company's intellectual resources. If people are unwilling to implement knowledge management, any investment, infrastructure, and technology will be useless in this way (Hwang et al, 2018). The organization must change its motivational activity in the direction of knowledge management (Davenport et al., 1998), and to do this, it must have a wide variety of types of reward structure and balance between the obvious and internal rewards. The most effective way is to use rewards for sharing knowledge at the start of KM activities.

Leadership and Management Support: Leadership plays a key role in the success of KM (Holsapple \& Jushi, 2000). Leaders use the business strategy to survive and maintain their superior position in today's dynamic environments. They also determine the organization's prospect and must align it with business strategies to improve the value of knowledge management in the organization (Mathi, 2004). The behavior of leaders has the greatest impact on the organization (Hassanali, 2002). Leaders are the pattern of others, and they present a favorable behavioral sample in relation to knowledge management. The leadership style and the strategic role of the leader can promote the elementary process and provide ideas for improvement and support (Forcadell \& Guadamillas, 2002). Other leadership abilities in relation to knowledge management are: guiding the process of change, transferring and realizing the importance of knowledge management to employees, strengthening morale and creating a culture of encouraging the creation and sharing knowledge. 
Human Resource Management: Although human resource management is important for several purposes, the main goal here is to hire, train and retain human resources. Individuals are important because any change or introduction of new technology affects the workforce inside the organization. Therefore, measuring the organizational culture and readiness of individuals to accept new technologies is necessary (Ruikar et al., 2006). Individuals are the creators of knowledge in the organization and a major part of organizational knowledge is in their minds. In general, the discussion of individuals in the organization as human participants involves the skills and the roles of knowledge, motivation and self-reaction, reinforcement, learning/social networks, dialogues, coordination and creativity (Moffett et al., 2002). According to Ruggles (1998), 50 percent of the time and budget of knowledge management must be allocated to individuals. Organizational individuals must be consistent with organizational culture. Another crucial issue in knowledge management is the prevention of the exodus of knowledge by the withdrawal of experienced staff from the company.

Training: Training is considered as an important factor for the success of KM (Holsapple \& Jushi, 2000; Mathie, 2004). So as to manage knowledge successfully, it is essential to invest in management and staff training. Members of the organization must be aware of the need for knowledge management and precept it as a vital source of exhilaration and organizational growth. In addition, using of knowledge management systems and other KM tools must be taught to employees (Hwang, 2003). Also, individuals need to be trained to understand their new roles in carrying out their tasks related to knowledge.

Financial and credit resources: Financial resources are an important factor for the success of knowledge activities. Increasing financial resources for knowledge activities (for example, acquiring the knowledge required) may affect the effectiveness of this activity or the quality of its outcomes (positive or negative) (Holsapple \& Joshi, 2000). However, since resource provision is one of the main concerns of the organizations, especially in small and medium enterprises, this must be considered in implementing the KM program. For example, the domain of the project must not exceed the available resources. Investment decisions must be based on a thorough review of the resources. Therefore, understanding the optimal way of acquisition, allocating and managing resources for the successful implementation of knowledge management in organizations is important. Financial support is essential for investing in a technical system.

Measurement: In fact, the measurement involves evaluating the knowledge resources and how it is processed (Holsapple \& Joshi, 2000). A plan, such as knowledge management, is always at risk to stay within the scope of the slogan. The way out of this position is measurement. Proverbs such as "something that cannot be measured cannot be managed" and "what is measured is done" is about knowledge management. Measurement enables the organization to track the progress of knowledge management and determine its benefits and effectiveness. Indeed, measurement is the basis for evaluating, comparing, controlling and improving the performance of organizations' knowledge management (Hassanali, 2002). Processes and activities: processes are activities that are carried out for a particular purpose, and include business rules and procedures of the organization (Ruikar et al., 2005). Here, we refer to the processes that scientists use to achieve the goals and mission of the organization. According to Ruggles (1998), in implementing KM, 25 percent of time and budget is allocated to the processes. Knowledge management processes are the processes that are conducted with knowledge within the organization. The number of processes in the field of knowledge management is numerous. For example, Alavi and Leidner (2001) presented four main processes: creation, storage and retrieval, transmission, and deployment.

Structure: Individuals work within an organizational structure that support organizational processes to achieve a company's overall strategy (Santoro \& Gopalakrishnan, 2000). A structure is a set of solutions for assigning different tasks between individuals and describes how to coordinate these tasks. The importance of organizational structure has been highlighted in the successful implementation of knowledge management. The successful implementation of the KM strategy is dependent on the flexible structure and the elimination of control and traditional monitoring systems (Forcadell \& Guadamillas, 2002). According to Ostroff (1999), flat organizations are more appropriate for the information age. 
Table 3

Success factors of knowledge management from the viewpoint of experts

\begin{tabular}{|c|c|}
\hline Source & Success factors of knowledge management \\
\hline $\begin{array}{l}\text { Sohrabi } \\
\text { et al., } 2009\end{array}$ & Infrastructure, Structure, Culture, Change perspective, Change support \\
\hline $\begin{array}{l}\text { Hung et al., } \\
\quad 2005\end{array}$ & $\begin{array}{l}\text { Performance evaluation, Information systems infrastructure, Strengthening employees, Employees in- } \\
\text { volvement, Trustworthy teamwork, Leadership and senior management commitment }\end{array}$ \\
\hline Mathi, 2004 & $\begin{array}{l}\text { Information systems structure, Sharing and obtaining knowledge, Organizational policy, Performance } \\
\text { evaluation, Patterning, Training, Leadership }\end{array}$ \\
\hline $\begin{array}{l}\text { Snyman \& } \\
\text { Kruger, } \\
2004\end{array}$ & $\begin{array}{l}\text { Technology environment, Systemic business, Human processes, Culture and discipline, Organization } \\
\text { strategy }\end{array}$ \\
\hline $\begin{array}{l}\text { Koskinen } \\
\text { et al., } 2003\end{array}$ & Transferring vital tacit knowledge, Obtaining vital tacit knowledge, Identifying vital tacit knowledge \\
\hline $\begin{array}{l}\text { Forcadell \& } \\
\text { Guadamillas, } \\
\quad 2002\end{array}$ & $\begin{array}{l}\text { Individuals, Creativity capability, Organization culture, Leadership method, Knowledge management } \\
\text { tools, Knowledge, management strategy } \\
\text { Structure }\end{array}$ \\
\hline $\begin{array}{l}\text { Kemp et al., } \\
2001\end{array}$ & $\begin{array}{l}\text { Technical maturity, Evolutionary, process, Flexible, frame work, Systemic approach, Real expectations, } \\
\text { Financial support, Clear goals }\end{array}$ \\
\hline $\begin{array}{l}\text { Alavi \& } \\
\text { Liedner, } \\
2001\end{array}$ & Technology, Measurement, Culture, Organizational issues \\
\hline Chait, 2000 & $\begin{array}{l}\text { Creating Effective Culture, Infrastructure management, Process management, Culture management, con- } \\
\text { tent management, Ensure insight and alignment }\end{array}$ \\
\hline $\begin{array}{c}\text { Cross \& } \\
\text { Baird, } 2000\end{array}$ & Improving, organizational learning \\
\hline Dixon, 2000 & $\begin{array}{l}\text { Identifying specific groups requiring specific knowledge, Alignment of knowledge management with or- } \\
\text { ganizational goals }\end{array}$ \\
\hline $\begin{array}{l}\text { Holsapple \& } \\
\text { Jushi, } 2000\end{array}$ & $\begin{array}{l}\text { Training, Competition, Communications, Markets, Government status, Strategy, Human, Coordination, } \\
\text { Infrastructure, Knowledge resources, } \\
\text { Infrastructure, Leadership, Technology, Measurement, Time pressure, Control, Financial resources }\end{array}$ \\
\hline
\end{tabular}

Flat companies are more flexible in environments with fast and competitive changes of business (Ruikar et al., 2005). Communications: Communications must be inclusive and repetitive. In many organizations, talking to colleagues is considered to be a non-value-added activity, while organizations must pay attention to the use of unofficial communication channels to share knowledge (Soliman \& Spooner, 2000). Without the constant flow of communications and ideas, the creation of knowledge does not take place. Sharing knowledge through face-to-face communication, collaborative work groups, and a culture that supports the sharing of knowledge, learning and development of individual skills is developed (Chong, 2006). Effective conversations in the group are essential for knowledge acquisition and sharing. Conversation is a way of sharing the knowledge of experts with others (Moffett et al., 2002), which is usually done at informal meetings. Table 3 shows a summary of the success factors of knowledge management from the point of view of the experts.

\section{Research Methodology}

This is an apply research and descriptive in nature. In order to collect the required data of this research, a researcher-made questionnaire was used. To ensure the formal and content validity of the questionnaire, the questionnaire was provided to 5 faculty members in the field of knowledge management and their views were obtained; Then the items they agreed on were used in the questionnaire and the cases in disagreement were resolved; Their corrective comments were also presented in the questionnaire and the questionnaire was returned to them. The questionnaire was assessed appropriate to evaluate the factors by consensus. Cronbach's alpha method was used to ensure the reliability of the questionnaire; a sample of 40 active employees in the field of knowledge management of the university was asked to fill in the questionnaire and the obtained data were analyzed and the results are presented in Table 4. 
Table 4

Reliability of the first questionnaire by using Cronbach's alpha method

\begin{tabular}{cccc}
\hline Scale & Alpha coefficient & Number of items & Number of subjects \\
\hline Cronbach's Alpha & 0.83 & 76 & 40 \\
\hline
\end{tabular}

As can be seen, Cronbach's alpha coefficient for the factors affecting the use of KM tools is 0.83 . Christmann and Van Aelst (2006) stated that for subjects used for research purposes, a correlation of 0.70 or more is sufficient. Therefore, according to the obtained coefficient, the questionnaire can be used in this study. The statistical population of this study is 210 people who are all faculty members and staff of the corporate university under study. Considering the constraints of the statistical society, 147 professors and university staff were selected through a targeted sampling method as a statistical sample.

Due to the specialty topic, a workshop was conducted in the form of a knowledge-based course with the presence of the statistical sample of the research and at the end of the course, the questionnaire was distributed. Data were analyzed by SPSS software by using descriptive statistics such as mean, standard deviation, variance and inferential statistics ( $\mathrm{t}$ test and Friedman test).

\section{Findings}

In order to identify the factors affecting the success of KM tools in the research projects of the university, in the first stage, by using the research literature, the factors affecting the success of KM tools were gathered. In the second stage, these factors were provided to the statistical sample specified in the university studied and they were asked to confirm or reject the validity of these factors and, in the next step, in an interview with the experts, they were asked to present, in addition to the identified factors in the research literature, the other key factors that contribute to the success of KM tools in the research projects of the university. Table 5 shows descriptive statistics indexes of the success factors of using knowledge management tools. The number of accepted questionnaires is 147 .

\section{Table 5}

Frequency distribution of descriptive statistics indexes of success factors of using tools

\begin{tabular}{|c|c|c|c|c|c|c|}
\hline Variable name & Domain & Lowest & Most & Mean & $\begin{array}{l}\text { Standard de- } \\
\text { viation }\end{array}$ & Variance \\
\hline Culture & 1.33 & 3.11 & 4.44 & 3.8768 & 0.27283 & 0.074 \\
\hline $\begin{array}{l}\text { Information } \\
\text { technology }\end{array}$ & 1.33 & 3.33 & 4.67 & 4.0907 & 0.24692 & 0.061 \\
\hline Strategy and goal & 2 & 2.6 & 4.6 & 3.6884 & 0.3833 & 0.147 \\
\hline $\begin{array}{l}\text { Organizational } \\
\text { infrastructure }\end{array}$ & 1.75 & 2.75 & 4.5 & 3.7296 & 0.38874 & 0.151 \\
\hline $\begin{array}{l}\text { Employees } \\
\text { motivation }\end{array}$ & 1.5 & 3.5 & 5 & 4.4252 & 0.35163 & 0.124 \\
\hline $\begin{array}{l}\text { Leadership and man- } \\
\text { agement } \\
\text { support }\end{array}$ & 1.6 & 3 & 4.6 & 4.0095 & 0.31781 & 0.101 \\
\hline $\begin{array}{c}\text { Human resources man- } \\
\text { agement }\end{array}$ & 1.75 & 3.25 & 5 & 4.2024 & 0.35275 & 0.124 \\
\hline Training & 1.4 & 3.4 & 4.8 & 4.0435 & 0.31188 & 0.097 \\
\hline $\begin{array}{c}\text { Financial and credit re- } \\
\text { sources }\end{array}$ & 1.71 & 3.14 & 4.86 & 4.1866 & 0.2694 & 0.073 \\
\hline Measurement & 1.18 & 3.18 & 4.36 & 3.7854 & 0.24098 & 0.058 \\
\hline $\begin{array}{l}\text { Processes and } \\
\text { activities }\end{array}$ & 1.4 & 3.4 & 4.8 & 4.0095 & 0.31695 & 0.1 \\
\hline Structure & 2 & 3 & 5 & 3.9524 & 0.37841 & 0.143 \\
\hline Communications & 1.83 & 2.67 & 4.5 & 3.6145 & 0.35693 & 0.127 \\
\hline
\end{tabular}

In order to know the significance level of the 13 factors affecting the success of KM tools, single-sample t-test was used, the results of which are shown in Table 6. 
Table 6

Table of comparison of the studied variables (with an average of 3 based on 5 point Likert scale)

\begin{tabular}{ccccc}
\hline Name of variable & Average & Standard deviation & Average difference & t value \\
\hline & 3.8768 & 0.27283 & 0.8768 & 38.965 \\
Information technology & 4.0907 & 0.24692 & 1.0907 & 53.556 \\
Strategy and goal & 3.6884 & 0.3833 & 0.68844 & 21.776 \\
Organizational infrastructure & 3.7296 & 0.38874 & 0.72959 & 22.755 \\
Employees motivation & 4.4252 & 0.35163 & 1.42517 & 49.141 \\
Leadership and management sup- & 4.0095 & 0.31781 & 1.00952 & 38.513 \\
port & 4.2024 & 0.35275 & 1.20238 & 41.328 \\
Human resources management & 4.0435 & 0.31188 & 1.04354 & 40.567 \\
Training & 4.1866 & 0.2694 & 1.18659 & 53.402 \\
Financial and credit resources & 3.7854 & 0.24098 & 0.78541 & 39.516 \\
Measurement & 4.0095 & 0.31695 & 1.00952 & 38.618 \\
Processes and activities & 3.9524 & 0.37841 & 0.95238 & 30.514 \\
Structure & 3.6145 & 0.35693 & 0.61451 & 20.874 \\
\hline Communications & & & &
\end{tabular}

$\mathrm{N}=147 ; \mathrm{DF}=147 ;$ sig=0.00; $\mathrm{P}<0.01$

The status of these factors in the knowledge management cycle of research projects in the studied university is higher than the average and is considered as effective factors in the KMS. In this research, "employees' motivation" with number 49.141, maintains the highest value of $\mathrm{t}$ and the "relationship" with 20.874 had the lowest value of $t$.

Friedman statistical test was used to compare the approved factors above and their prioritization in the knowledge management system of the studied university. The results are summarized in Table 7 . It needs to be explained that this test has examined the difference between the total rank of the three correlated groups or more and does not have necessary sensitivity in the case of the pairwise comparisons. Therefore, the differences observed in this Table indicate the order of total rankings and the difference between the rankings cannot be deduced from this test

Table 7

Comparison and prioritization of the success factors of using tools in the knowledge management cycle of the university under study

\begin{tabular}{lcc}
\hline factor & Average & Mean rank \\
\hline Culture & 3.8768 & 5.97 \\
Information Technology & 4.0907 & 8.32 \\
Strategy and goal & 3.6884 & 4.41 \\
Organizational infrastructure & 3.7296 & 4.83 \\
Employees motivation & 4.4252 & 11.06 \\
Leadership and management support & 4.0095 & 7.38 \\
Human resources management & 4.2024 & 9.17 \\
Training & 4.0435 & 7.61 \\
Financial and credit resources & 4.1866 & 9.36 \\
Measurement & 3.7854 & 4.93 \\
Processes and activities & 4.0095 & 7.19 \\
Structure & 3.9524 & 6.92 \\
Communications & 3.6145 & 3.84 \\
\hline $\mathrm{N}=147 ; \mathrm{DF}=12 \cdot \mathrm{Chi-S} q u a r=548068 ;$ sic=0.00; $<<0.01$ & &
\end{tabular}

As can be seen, the value of Chi-Square calculated for factors influencing the knowledge management cycle with 12 degrees of freedom is 548.068 which is statistically significant at the level $(0.01>\mathrm{P})$; Therefore, there are differences between the factors mentioned in the above table and according to the 
means ranking, the factors listed in Table 8 are in higher priorities respectively.

\section{Table 8}

Success Factors of Knowledge Management Tools in priority order

\begin{tabular}{lc}
\hline Factor & Mean rank \\
\hline Employee motivation & 11.06 \\
Financial and credit resources & 9.36 \\
Human resources management & 9.17 \\
Information Technology & 8.32 \\
Training & 7.61 \\
Leadership and management support & 7.38 \\
Processes and activities & 7.19 \\
Structure & 6.92 \\
Culture & 5.97 \\
Measurement & 4.93 \\
Organizational infrastructure & 4.83 \\
Strategy and goal & 4.41 \\
Communications & 3.84 \\
\hline
\end{tabular}

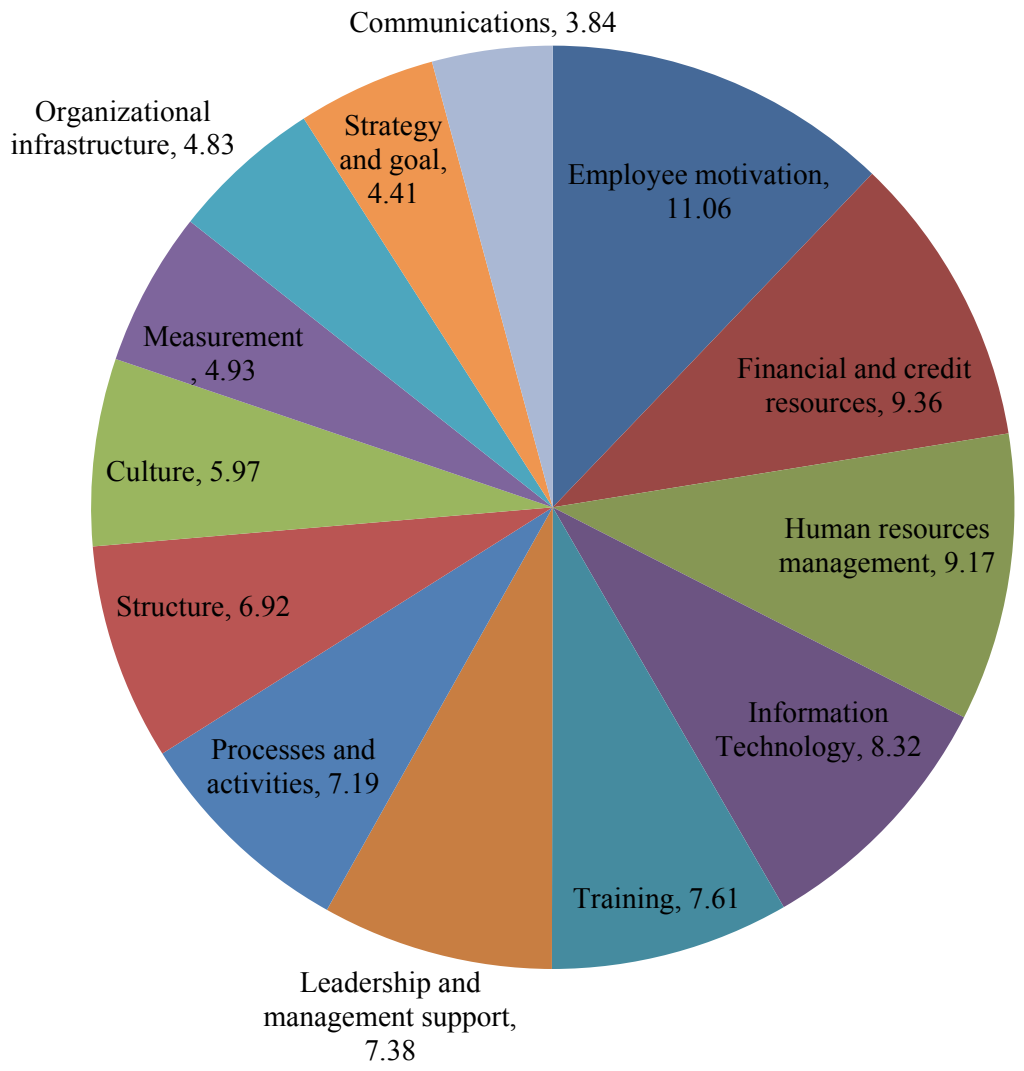

Fig. 2. Success Factors of Knowledge Management Tools 


\section{Conclusion}

In the present study, the most important factors for the success of using knowledge management tools in the studied university are employee motivation, resources, human resources management, information technology, education, leadership and management support, processes and activities, structure, culture, measurement, organizational infrastructure, strategy and goal, and communication. As we can see, the first three factors (motivation of staff, resources, human resources management) are human-motivational in nature, and they are in some way related to the empowerment of employees, and it seems that in the studied university, it needs to pay more attention to the motivational factors, and the quantity and speed of payment of doing researches; Considering the university hierarchy and the high degree of administrative formalities, the results are in line with the current state of the university and confirms the necessity of promoting the incentive system and eliminating administrative bureaucracy for payment. In this regard, the results of studies by other researchers also confirm the findings of the research, For example, Davenport et al. (1998), argued that the organization must change its motivational activity in the direction of knowledge management; Researchers who care about human values argue that job satisfaction must be one of the main goals of the organization, and organizations must provide conditions that keep employees satisfied (Sarker et al., 2003). The information technology factor is ranked next to human-motivational factors and, in addition to its importance, confirms the necessity of strengthening this dimension. Knowledge management can play a very important role with the proper use of information technology (Alavi \& Leidner, 2001).

Developing an intranet and creating computer centers can also play a key role in knowledge sharing. By reviewing the appropriate tools in the knowledge sharing process of the research projects of the university, IT-based tools were ranked higher. In the meantime, the research findings are consistent with the current status of the university and confirms the development of information technology. Among the confirmed factors for the success of the use of KM tools, training has the next rank. To manage knowledge successfully, it is necessary to invest sufficiently in management and staff training. Members of the organization must be aware of the need for knowledge management and its perception as vital source of vitality and organizational growth. This can be achieved by providing basic training to the staff. In addition, the use of knowledge management systems and other KM tools must be taught to the employees. By doing this training, one can be sure of their ability to use the capabilities of these tools. Also, people need to be trained to understand their new roles in carrying out their tasks related to knowledge. Equipping the staff with knowledge sharing skills and creativity and innovation is also important (Hasani \& Sheikhesmaeili, 2016).

In the analysis carried out, the mean rank of the factors of culture, measurement, organizational infrastructure, strategy, and goal, and communications are in the next lines, and this question is put forward in mind, which, despite the high value that the factors mentioned in the literature of the research and also seen in the findings of other researchers, why do these factors rank as the next? In response to this question, it should be said that, regarding the confirmation of the factors mentioned in the present research, respondents also recognized the importance of these factors. Therefore, by comparing and adapting the current status of the studied university, with each of the mentioned factors, the status of the factors is evaluated at an appropriate level and is ranked in the lower priority by the respondents.

\section{Acknowledgement}

The authors would like to thank the anonymous referees for constructive comments on earlier version of this paper. 


\section{References}

Alavi M., Leidner D.E., (2001). Knowledge management and knowledge management systems: Conceptual foundations and research issues. MIS Quarterly, 25(1), 107-136.

Alekseev, A. (2010). Knowledge Management in Project-Based Organisations: The Success Criteria and Best Practises. Master's thesis, Sweden: chalmers university of technology \& northumbria university.

Bharadwaj, A. S. (2000). A resource-based perspective on information technology capability and firm performance: an empirical investigation. MIS Quarterly, 24(1),169-196.

Bolisani, E., \& Bratianu, C. (2017). Knowledge strategy planning: an integrated approach to manage uncertainty, turbulence, and dynamics. Journal of Knowledge Management, 21(2), 233-253.

Chait, L. P. (2000). Creating a successful knowledge management system. IEEE Engineering Management Review, 28(2), 92-95.

Chaudhry, A. B. (2005). Knowledge sharing practices in Asian institutions: a multi-cultural perspective from Singapore. IFLA 2005.

Choy Chong, S. (2006). KM critical success factors: a comparison of perceived importance versus implementation in Malaysian ICT companies. The learning organization, 13(3), 230-256.

Christmann, A., \& Van Aelst, S. (2006). Robust estimation of Cronbach's alpha. Journal of Multivariate Analysis, 97(7), 1660-1674.

Civi, E. (2000). Knowledge management as a competitive asset: a review. Marketing Intelligence \& Planning, 18(4), 166-174.

Crocetti, C. (2001). Corporate learning: A knowledge management perspective. The Internet and higher education, 4(3-4), 271-285.

Cross, R., \& Baird, L. (2000). Technology is not enough: Improving performance by building organizational memory. Sloan Management Review, 41(3), 69.

Davenport, T. H., Delong, D. W., Beers, M. C. (1998). Successful knowledge management projects. Sloan Management Review, 39(2), 43-57.

Demarest, M. (1997). Understanding knowledge management. Long range planning, 30(3), 374-384.

Dixon, N. M. (2000). Common knowledge: How companies thrive by sharing what they know. Harvard Business School Press, Boston.

Forcadell, F. J., \& Guadamillas, F. (2002). A case study on the implementation of a knowledge management strategy oriented to innovation. Knowledge and Process Management, 9(3), 162-171.

Frey, P., Lindner, F., Muller, A., \& Wald, A. (2009, January). Project Knowledge Management Organizational Design and Success Factors-An Empirical Study in Germany. In System Sciences, 2009. HICSS'09. 42nd Hawaii International Conference on (pp. 1-14). IEEE.

Ghomi, H. R. (2014). Designing a architecture for utilizing appropriate knowledge management tool in academic research projects. Master's thesis, Iran: Iran University of Science and Technology.

Hasani, K., \& Sheikhesmaeili, S. (2016). Knowledge management and employee empowerment: A study of higher education institutions. Kybernetes, 45(2), 337-355.

Hassanali, F. (2002). Critical success factors of knowledge management, APQC. available: http://www.scribd.com/doc/96648076/HASSANALI-Critical-Success-Factors-of Knowledge -Management

Holsapple, C. W., \& Joshi, K. D. (2000). An investigation of factors that influence the management of knowledge in organizations. The Journal of Strategic Information Systems, 9(2-3), 235-261.

Huang, Y. C., \& Jim Wu, Y. C. (2010). Intellectual capital and knowledge productivity: the Taiwan biotech industry. Management decision, 48(4), 580-599.

Hung, Y. C., Huang, S. M., Lin, Q. P., \& -Tsai, M. L. (2005). Critical factors in adopting a knowledge management system for the pharmaceutical industry. Industrial Management \& Data Systems, 105(2), 164-183.

Hwang, A. (2003). Training strategies in the management of knowledge. Journal of Knowledge Management, 7(3), 92-104.

Hwang, Y., Lin, H., \& Shin, D. (2018). Knowledge system commitment and knowledge sharing intention: The role of personal information management motivation. International Journal of Information 
Management, 39(2018), 220-227.

Kemp, J., Pudlatz, M., Perez, P., \& Ortega, A. M. (2001). KM technologies and tools. In European KM Forum.

Koskinen, K. U., Pihlanto, P., \& Vanharanta, H. (2003). Tacit knowledge acquisition and sharing in a project work context. International journal of project management, 21(4), 281-290.

Leibowitz, J. (1999). Key ingredients to the success of an organization's knowledge management strategy. Knowledge and Process Management, 6(1), 37-40.

Mårtensson, M. (2000). A critical review of knowledge management as a management tool. Journal of knowledge management, 4(3), 204-216.

Mathi, K. (2004). Key success factors for knowledge management. MBA: International Business Management\& Consulting. Master thesis. Germany, university of applied sciences.

Moffett, S., McAdam, R., \& Parkinson, S. (2002). Developing a model for technology and cultural factors in knowledge management: a factor analysis. Knowledge and Process Management, 9(4), 237255.

Ostroff, F. (1999). The horizontal organization: What the organization of the future looks like and how it delivers value to customers. Oxford University Press on Demand.

Rademakers, M. (2005). Corporate universities: driving force of knowledge innovation. Journal of workplace Learning, 17(1/2), 130-136.

Ruggles, R. (1998). The state of the notion: knowledge management in practice. California management review, 40(3), 80-89.

Ruikar, K., Anumba, C. J., \& Carrillo, P. M. (2006). VERDICT-An e-readiness assessment application for construction companies. Automation in construction, 15(1), 98-110.

Sage, A. P., \& Rouse, W. B. (1999). Information systems frontiers in knowledge management. Information systems frontiers, 1(3), 205-219.

Santoro, M. D., \& Gopalakrishnan, S. (2000). The institutionalization of knowledge transfer activities within industry-university collaborative ventures. Journal of engineering and technology management, 17(3-4), 299-319.

Saraph, J. V., Benson, P. G., \& Schroeder, R. G. (1989). An instrument for measuring the critical factors of quality management. Decision sciences, 20(4), 810-829.

Sarker, S.J., Crossman, A. and Chinmeteepituck, P. (2003). The relationship of age and length of service with job satisfaction: an examination of hotel employees in Thailand. Journal of Managerial Psychology, 18(7/8), 745-758.

Snyman, R., \& Kruger, C. J. (2004). The interdependency between strategic management and strategic knowledge management. Journal of knowledge management, 8(1), 5-19.

Sohrabi, B., Mohammadi, K., \& Khanlari, A. (2009). Organizational Readiness Assessment for Knowledge Management . International Journal of Knowledge Management, 5(1), 29-45.

Soliman, F., \& Spooner, K. (2000). Strategies for implementing knowledge management: role of human resources management. Journal of knowledge management, 4(4), 337-345.

Sunassee, N. N., \& Sewry, D. A. (2003, September). An investigation of knowledge management implementation strategies. In Proceedings of the 2003 annual research conference of the South African institute of computer scientists and information technologists on Enablement through technology (pp. 24-36). South African Institute for Computer Scientists and Information Technologists.

Tanriverdi, H. (2005). Information technology relatedness, knowledge management capability: and performance of multi business firms. MIS Quarterly, 29(2), 311-334.

Terzieva, M. (2014). Project Knowledge Management: How Organizations Learn from Experience. Procedia Technology, 16(2014), 1086-1095.

Tseng, S. (2008). The effects of information technology on knowledge management systems. Expert Systems with Applications, 35(1-2), 150-160.

Wade, M., \& Hulland, J. (2004). The resource-based view and information systems research: Review, extension, and suggestions for future research. MIS quarterly, 28(1), 107-142.

Wiig, K. M. (1997). Knowledge management: an introduction and perspective. Journal of knowledge Management, 1(1), 6-14. 
Young, R. (2010). Knowledge management tools and techniques manual. Asian Productivity Organization, 98 .

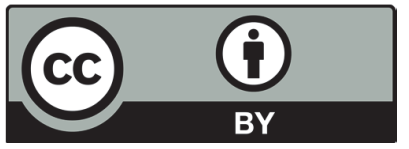

(C) 2018 by the authors; licensee Growing Science, Canada. This is an open access article distributed under the terms and conditions of the Creative Commons Attribution (CCBY) license (http://creativecommons.org/licenses/by/4.0/). 